\title{
RECURRENT PALATAL FISTULA AND NASAL REGURGITATION;
}

Anteriorly based dorsal tongue flap: A reliable solution.

\section{Dr. Irfan Ishaq, Prof. GhulaM Qadir Fayyaz}

ABSTRACT.....Background: Post Palatoplasty fistulas are the common complications seen after cleft palate repair. This produce various symptoms including regurgitation of fluids into nasal cavity, interference with normal speech and middle ear problems . Although small fistulas can be successfully treated with local flaps such as palatal or buccal mucosal flaps, large fistulas are difficult to treat. Because of rich blood supply, tongue is a suitable and convenient source of large flap. The anteriorly based dorsal tongue flap is a safe and effective method for closure of relatively large recurrent palatal fistula without any functional impairment of donor site. Objective: To determine the success rate of Tongue flap in correction of the nasal regurgitation in recurrent palatal fistulas Duration of study: 12 months from 16 th July 2010 to 15th July 2011. Study design: It was descriptive case series. Settings: This study was carried out in the department of plastic surgery Services institute of medical sciences, Services Hospital Lahore. Methods: Forty patients who were having recurrent palatal fistula included in this study. All underwent palatal fistula repair by dorsal tongue flap. Each patient was followed after one month of operation for fistula closure and correction of nasal regurgitation. Results: In this study 65 percent of the patients were male, while 35 percent of them were female. 21 (52.5\%) of the patients belonged to age group 10-15 years, while 14 (35.0\%) of the respondents had 16 20 years of age and remaining 5 (12.5\%) of them had 21-30 years of age. The 90 percent (out of 40 ) of the patients had complete fistula closure, while only 10.0 percent of them had not complete fistula closure. Nasal regurgitation was corrected in 38 (95\%) of the patients and remaining 2 ( $5 \%$ ) patients had un-corrected nasal regurgitation. Conclusions: Tongue flap is a effective and reliable method of treatment, not only for palatal fistula closure but also treating nasal regurgitation which is a social stigma for patients in recalcitrant palatal fistula.

Key words: Tongue flap, Palate, Fistula, Nasal regurgitation

\section{Article Citation}

Ishaq I, Fayyaz GQ. Recurrent Palatal Fistula And Nasal Regurgitation; Anteriorly based dorsal tongue flap: A reliable solution..

Professional Med J 2013;20(3): 390-398.

\section{INTRODUCTION}

Cleft palate is common congenital anomly ${ }^{1}$. Which occurs during the $5^{\text {th }}$ week of embryonic development. Several techniques has been describes which reflects the goals of complete separation of oral and nasal cavity, velar muscle repair, assisting normal speech and face development. Fistula is the commonest and troublesome complication associated with cleft palate surgery ${ }^{2}$. Which is an abnormal communication between oral cavity and nose. These fistulas more frequently occur in the hard palate ${ }^{3}$. The problems caused by palatal fistulas depend on their size and patient's ability to accommodate the smaller ones. Palatal fistula can be classified by size as small $(<3 \mathrm{~mm})$, medium $(3-5 \mathrm{~mm})$ and large $(>5 \mathrm{~mm})$ while Shurtz classified as pinpoint, slit, oval and total dehiscence.
Nasal regurgitation is one of the major symptom of fistula which causes entrance of food or liquid, from nose to mouth and vice versa which may be socially embarrassing; foul smell and irritation as well as nasal secretions enter mouth causing bad taste and breathe resulting in poor oral hygiene ${ }^{3}$. Speech related, symptoms include nasal escape, hyper nasal resonance, and velopharyngeal incompetence ${ }^{4}$. Repair of Postpalatoplasty fistulas is a difficult task. Recurrence rates are approximately 4 to 37 percent ${ }^{5}$. Factors which have been reported to increase the incidence of palatal fistulae, including tension along the palate repair, upper respiratory infection, hemorrhage, absent multi layer closure, and increasing cleft severity ${ }^{6}$. These fistulas may vary greatly in size and location, ranging from small defect in buccal sulcus to a large opening that extends most of the length of the palate. A large number of 
inappropriately treated patients require revisional surgery ${ }^{7}$.

Previous palatal surgery has caused scaring of adjacent palatal mucoperiosteum, resulting in insufficient healthy tissue for fistula closure. Due to this problem an extensive operation is needed to resolve even a small defect. The tongue flap is thus suitable for closure of a large and persistent palatal fistula, in heavily scarred palates and in cases with previous attempts have been unsuccessful ${ }^{8}$. Fistula correction with local flaps often fails in these sort of cases. Tongue flap owing to its muscular bulk and excellent vascularity is claimed to be effective in occluding even large palatal fistula. Guerrero-Santos and Altamirano ${ }^{9}$ in 1966 were first to describe the use of Tongue flap to close palatal fistulae secondary to cleft palate repair. This study focuses on efficacy of dorsal Tongue flap in patients having secondary palatal fistula. Purpose of this study was to assess the effectiveness of Tongue flap in fistula closure and correction of nasal regurgitation ${ }^{10}$. Thus those patients which remained untreated due to large fistula size can be treated by using this technique.

\section{MATERIAL AND METHODS}

From July 2010 to July 2011 forty patients Study were studied in plastic surgery department, Services Hospital, Lahore. It was descriptive case series and sampling technique was Non probability purposive sampling. Patients age from 10-30 years of either gender with at least one failed operation and having fistula size between $1.5 \mathrm{~cm}$ to $4 \mathrm{~cm}$ were included. Patients with palatal perforation due to heroin addiction, leprosy or cancrum oris. were excluded from study. Informed written Consent was taken from all patients. After proper assessment dorsal tongue flap employed for fistula repair in all patients. The flap base was detached at two weeks postoperatively. The patients were followed up for 4 weeks postoperatively and all the findings were recorded and then analyzed using SPSS statistical software. A P value of $<0.05$ was considered statistically significant. Data was stratifies for the size of fistula $\left(<3 \mathrm{~cm}^{2}, 3 \mathrm{~cm}^{2},>3 \mathrm{~cm}^{2}\right)$

\section{SURGICAL TECHNIQUE}

The Surgery was done under general anesthesia. Lignocaine with adrenaline 1:200,000 was infiltrated in to the operating field. Tongue was held in position with 2-0 silk. Marking was done on the dorsal side of the tongue a litter more than the side of the palatal defect. Nasal layer was reconstructed by turning down the oral mucosal flaps. Raw area was created all around the defect $A$ transverse incision is made on the palate flap proximal to the rim of the fistula. this creates a sling for the suspension of the tongue pedicle. Base of the tongue flap kept 2.5 to $3.0 \mathrm{~cm}$ wide and length may be extended 5 to $6 \mathrm{~cm}$. Preserve as much of the tongue tip as possible Generally flaps are 5 to $7 \mathrm{~mm}$ thick, and include mucosa and sub adjacent Muscle, Avoid principal gustatory papillae in flap design and hematoma formation at the donor site with attention to hemostasis and obliteration of dead space. Once the tongue flap is raised, it may be widened by dividing the muscle on the undersurface of the flap with short incisions in a longitudinal direction. This is a two-stage procedure Detachment is done on the $14^{\text {th }}$ to $21^{\text {th }}$ postoperative day. Dorsal side of the tongue was closed primarily.

\section{RESULTS}

A total of 40 patients were included in this study from $16^{\text {th }}$ July 2010 to $15^{\text {th }}$ July 2011. All patients having recurrent palatal fistula with one or more previous failed operations. Dorsal Tongue flap was used to close the palatal fistula and correction of nasal regurgitation in all cases.

It was found that substantial proportion i.e. $65 \%$ were male and about one third i.e. 35\% were females. Regarding age group little more than a half $52.5 \%$ of the patients belonged to age group 10-15 years, while $35.0 \%$ of the respondents had $16-20$ years of age and remaining $12.5 \%$ of them had $21-30$ years of age. 
Mean age of the patients was 16.20 years with 4.183 standard deviation (Table-I).

\begin{tabular}{|c|c|c|}
\hline Gender & Frequency & Percentage \\
\hline Male & 26 & 65.0 \\
\hline Female & 14 & 35.0 \\
\hline Total & 40 & 100.0 \\
\hline Age category (in years) \\
\hline $10-15$ & 21 & 52.5 \\
\hline $16-20$ & 14 & 35.0 \\
\hline $21-30$ & 5 & 12.5 \\
\hline Total & 40 & 100.0 \\
\hline & Mean age $=\mathbf{1 6 . 2 0}$. Std. $=\mathbf{4 . 1 8 3}$ \\
\end{tabular}

Table-I. Gender frequencies and age group

A large majority i.e. 90 percent (out of 40 ) of the patients had complete fistula closure, while only 10 percent of them had not complete fistula closure (Table-II ). It was also found that nasal regurgitation was corrected in 38 (95\%) of the patients and remaining 2 (5\%) patients had un-corrected nasal regurgitation (Table-III). A significant number of the patients i.e. $27(67.5 \%)$ had less than $3 \mathrm{~cm}^{2}$ fistula size, while $6(15.0 \%)$ of them had $3 \mathrm{~cm}^{2}$ and 7 (17.5\%) of them had more than $3 \mathrm{~cm}^{2}$ size of palatal fistula (Table-IV).

\begin{tabular}{|c|c|c|}
\hline Complete Fistula closure & Frequency & Percentage \\
\hline Yes & 36 & 90.0 \\
\hline No & 4 & 10.0 \\
\hline Total & 40 & 100.0 \\
\hline
\end{tabular}

Table-II. Complete Fistula Closure

Chi-square value (11.039) shows a highly significant (P-value $=.004)$ association between complete fistula closure and size of palatal fistula. It was found that $27(67.5 \%)$ patients had less than $3 \mathrm{~cm}^{2}$ fistula size and all of them had complete fistula closure. On the other hand 6 patients had $3 \mathrm{~cm}^{2}$ fistula size, among them $5(12.5 \%)$ had complete fistula closure and 1 (2.5\%) of them had not complete fistula closure. Seven patient (17.5\%) had more than $3 \mathrm{~cm} 2$ fistula size, between them $4(10.0 \%)$ had complete fistula closure while $3(7.5 \%)$ had not complete fistula closure (Table-V).

\begin{tabular}{|c|c|c|}
\hline Nasal regurgitation Efficacy & Frequency & Percentage \\
\hline Correct & 38 & 95.0 \\
\hline No correct & 2 & 5.0 \\
\hline Total & 40 & 100.0 \\
\hline Table-III. Nasal regurgitation correction \\
\hline
\end{tabular}

\begin{tabular}{|c|c|c|}
\hline Size of palatal fistula & Frequency & Percentage \\
\hline Less than $3 \mathrm{~cm}^{2}$ & 27 & 67.5 \\
\hline $3 \mathrm{~cm}^{2}$ & 6 & 15.0 \\
\hline More than $3 \mathrm{~cm}^{2}$ & 7 & 17.5 \\
\hline Total & 40 & 100.0 \\
\hline \multicolumn{3}{|c|}{ Table-IV. Size of palatal fistula } \\
\hline
\end{tabular}

Chi-square value (7.0505) shows a highly significant $(P$-value $=.007)$ association between nasal regurgitation correction and size of palatal fistula. It was found that $27(67.5 \%)$ patients had less than 3 $\mathrm{cm}^{2}$ fistula size and all of them had corrected nasal regurgitation. Similarly 6 patients had $3 \mathrm{~cm}^{2}$ fistula size, and nasal regurgitation was corrected in all of them $6(15.0 \%)$. Seven patients $(17.5 \%)$ had more than $3 \mathrm{~cm}^{2}$ fistula size, between them $5(12.5 \%)$, the problem resolved while $2(5 \%)$ of them had still nasal regurgitation (Table-VI).

Type and severity of cleft ${ }^{16}$ is directly associated to the recurrence of fistulation. In our study failure of fistula closure was more in larger defects(Fig 3). Four patients out of 40 ended in recurrence of fistulation and 


\begin{tabular}{|c|c|c|c|c|}
\hline \multirow{2}{*}{$\begin{array}{l}\text { Complete } \\
\text { Fistula closure }\end{array}$} & \multicolumn{3}{|c|}{ Size of palatal fistula } & \multirow[t]{2}{*}{ Total } \\
\hline & Less than $3 \mathrm{~cm}^{2}$ & $3 \mathrm{~cm}^{2}$ & More than $3 \mathrm{~cm}^{2}$ & \\
\hline \multirow{2}{*}{ Yes } & 27 & 5 & 4 & 36 \\
\hline & $67.5 \%$ & $12.5 \%$ & $10.0 \%$ & $90.0 \%$ \\
\hline \multirow{2}{*}{ No } & 0 & 1 & 3 & 4 \\
\hline & $0 \%$ & $2.5 \%$ & $7.5 \%$ & $10.0 \%$ \\
\hline \multirow{2}{*}{ Total } & 27 & 6 & 7 & 40 \\
\hline & $67.5 \%$ & $15.0 \%$ & $17.5 \%$ & $100.0 \%$ \\
\hline
\end{tabular}

\begin{tabular}{|c|c|c|c|c|}
\hline \multirow{2}{*}{$\begin{array}{c}\text { Nasal Regurgitation } \\
\text { Efficacy }\end{array}$} & \multicolumn{3}{|c|}{ Size of palatal fistula } & \multirow[t]{2}{*}{ Total } \\
\hline & Less than $3 \mathrm{~cm}^{2}$ & $3 \mathrm{~cm}^{2}$ & More than $3 \mathrm{~cm}^{2}$ & \\
\hline \multirow{2}{*}{ Correct } & 27 & 6 & 5 & 38 \\
\hline & $67.5 \%$ & $15.0 \%$ & $12.5 \%$ & $95 \%$ \\
\hline \multirow{2}{*}{ No correct } & Nil & Nil & 2 & 2 \\
\hline & $0 \%$ & $0 \%$ & $5.0 \%$ & $5 \%$ \\
\hline \multirow{2}{*}{ Total } & 27 & 6 & 7 & 40 \\
\hline & $67.5 \%$ & $15.0 \%$ & $17.5 \%$ & $100.0 \%$ \\
\hline
\end{tabular}

three belongs to patients group with larger size of fistula (more than $3 \mathrm{~cm}^{2}$ ). Two patients out of forty subjectively explained that they still had the problem of regurgitation of semi solid fluids and liguids into the nose. These two patients belonged to the palatal defect group more than $3 \mathrm{~cm}^{2}$. Some authors claimed that closure of nasal side of the fistula is an essential part of the repair ${ }^{3}$ other have negate this issue ${ }^{16}$ and observed that even when the nasal side of the repair is not sealed in a watertight fashion, healing of the fistula is still possible as tongue flap on the oral side encompasses the defect beyond the limits of the fistula. In our technique we close nasal layer by turning down oral layer in every case. This step facilitates nasal regurgitation correction. Among these patients fistula recurrence and regurgitation were more in larger defects. Wound dehiscence was noted in three cases and partial flap necrosis in one case. Previous literature described that extensive use of the diathermy ${ }^{15}$ can result thermal injury and may affect healing process. An extensive tongue movement is another contributory factor in wound dehiscence. Limitation of speech is encouraged to avoid undue tension on the pedicle $e^{13,17}$. Various authors described different methods of tongue fixation in order to avoid such mishaps. Guerrero-Santos and Femandez ${ }^{18}$ used 


\begin{tabular}{|c|c|c|c|c|}
\hline \multirow{2}{*}{ Efficacy } & \multicolumn{3}{|c|}{ Size of palatal fistula } & \multirow{2}{*}{ Total } \\
\cline { 2 - 5 } & Less than $\mathbf{3} \mathbf{c m}^{\mathbf{2}}$ & $\mathbf{3} \mathbf{c m}^{\mathbf{2}}$ & More than $\mathbf{3} \mathbf{c m}^{\mathbf{2}}$ & \\
\hline \multirow{2}{*}{ Yes } & 27 & 5 & 4 & 36 \\
\cline { 2 - 5 } & $67.5 \%$ & $12.5 \%$ & $10.0 \%$ & $90.0 \%$ \\
\hline \multirow{2}{*}{ No } & 0 & 1 & 3 & 4 \\
\cline { 2 - 5 } & Nil & $2.5 \%$ & $7.5 \%$ & $10.0 \%$ \\
\hline \multirow{2}{*}{ Total } & 27 & 6 & $17.5 \%$ & $100.0 \%$ \\
\cline { 2 - 5 } & $67.5 \%$ & $15.0 \%$ & 70 \\
\hline
\end{tabular}
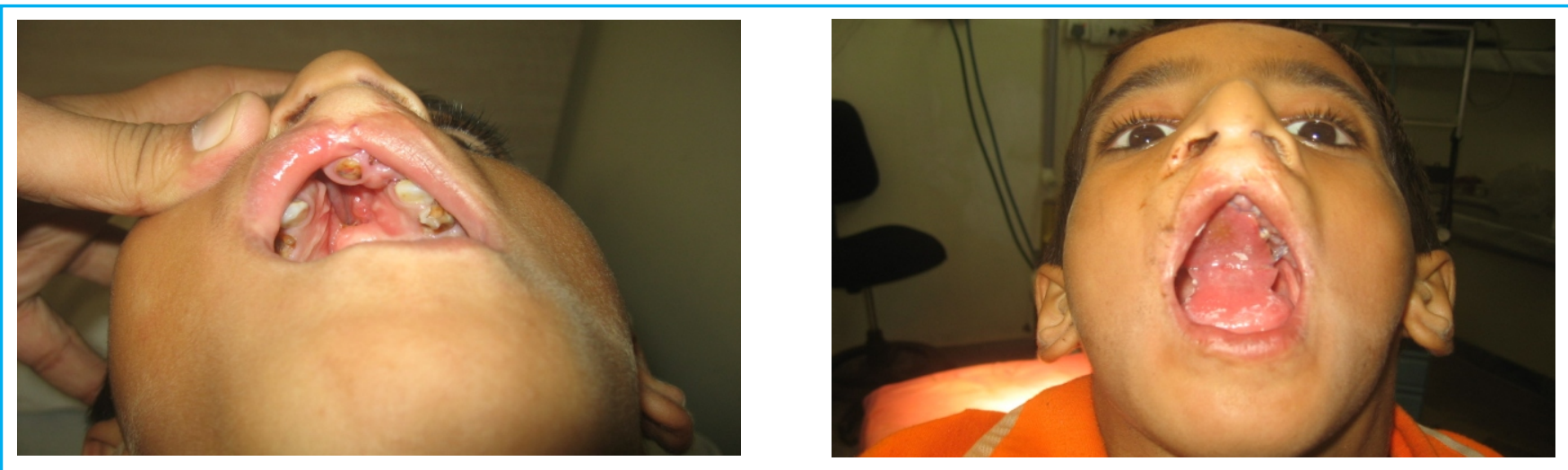

Figure 1 and 2. This 11 years old male patient had anterior palatal fistula of $(1.5 \mathrm{~cm})(2 \mathrm{~cm})$ size. He had right complete cleft palate.Post palatoplasty fistula results due to distal flap necrosis. Dorsal single layer tongue flap used for correction of defect.
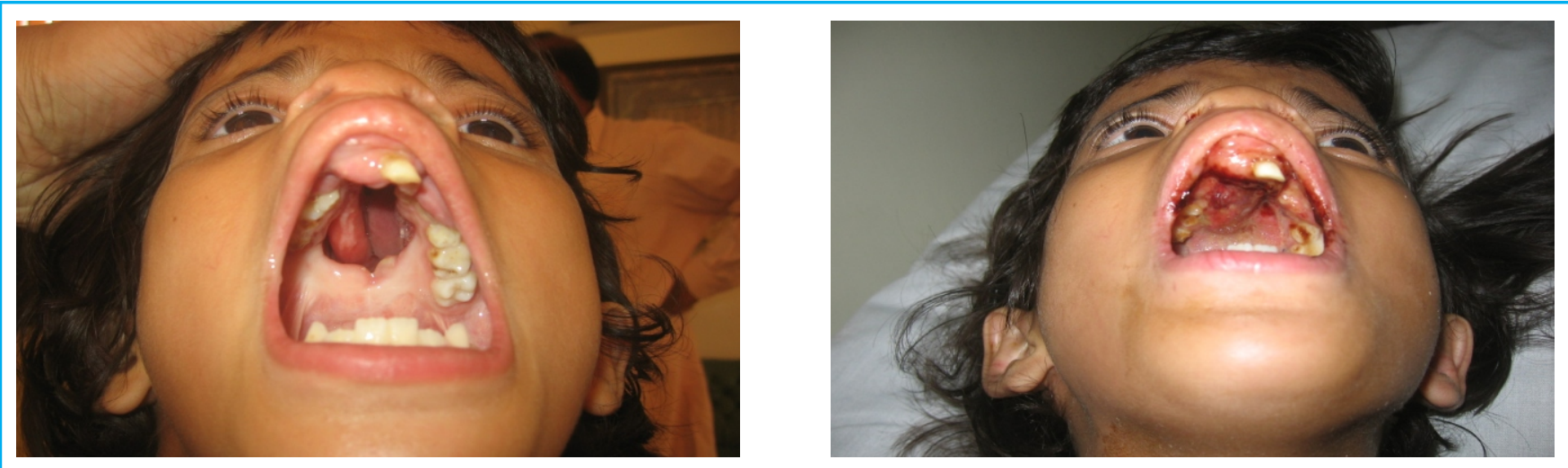

Figure 3 and 4 . This $13 y e a r s$ female patient had recurrent palatal fistula of $(5 \mathrm{~cm}) .(4 \mathrm{~cm})$ size. Anteriorly based tongue flap is used to close the fistula.Post operatively wound dehiscence was associated with persistent nasal regurgitation. 

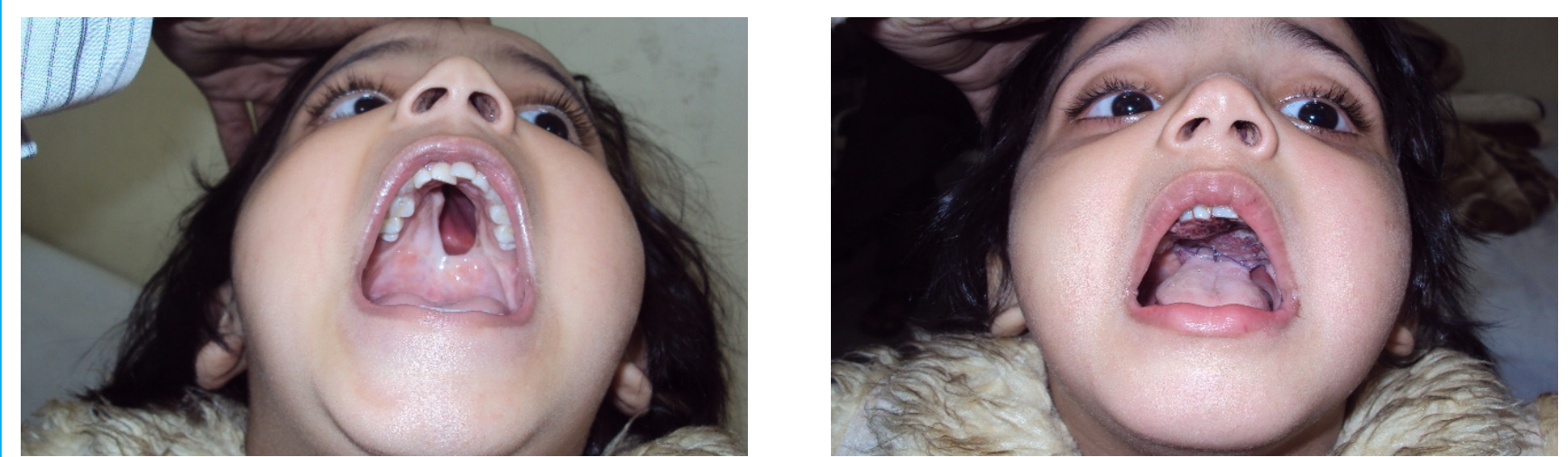

Figure 5 and 6 . This 10 years female patient had $(2.5 \mathrm{~cm})(3.5 \mathrm{~cm})$ palatal defect Left sided total mucoperiosteal flap necrosis distal to soft palate. Dorsal tongue flap was implemented.

wire sutured to the tongue tip passed through and tied to the upper lip. Kruchinsky ${ }^{19}$ described fixation of side of the tongue to the premolars. Guerrero-Santos et al placed a kirschner wire placed through the angle of mandible, transfixing the body of the tongue. In our case series we used vicryl suture to tie the tongue flap in palatal defect. Some studies claimed to raise a large flap (5-6 cm long) to ensure its vascular viability and allow considerable tongue movement without undue tension on the pedicle ${ }^{13}$. This also eliminate the need of different tongue fixation procedures. In addition, aggressive palatal shelf exposure around the defect allows both a watertight oral-side closure and an increased surface area for in growth of new blood vessels before flap division..Single layer closure of fistula by anteriorly based pedicled tongue flap is therefore indicated in recurrent palatal fistula for correction of nasal regurgitation that cannot be successfully treated by other local or distant flaps because of the size and/or position of the defect ${ }^{20}$.

Chi-square value (11.039) indicates a highly significant (P-value $=.004$ ) association between overall efficacy (i.e fistula closure and correction of nasal regurgitation) and size of palatal fistula. It was found that $27(67.5 \%)$ patients had less than $3 \mathrm{~cm}^{2}$ fistula size and all of them had overall efficacy. On the other hand 6 patients had $3 \mathrm{~cm}^{2}$ fistula size, among them 5 (12.5\%) had overall efficacy and 1 (2.5\%) of them had not overall efficacy. Seven patients (17.5\%) had more than $3 \mathrm{~cm}^{2}$ fistula size, between them 4 $(10.0 \%)$ had overall efficacy while $3(7.5 \%)$ had not overall efficacy (Table-VII).

\section{DISCUSSION}

Nasal regurgitation is very embarrassing situation faced by patients in which cleft palate repair ended in fistulation. Digested food material and liquids may regurgitate into nose as well as nasal secretions fall into mouth. This results foul smell in mouth, irritation, poor oral hygiene and speech disturbance Repairing of recurrent palatal fistula is one of the most challenging and difficult problem faced by cleft surgeons. Literature showed the recurrence rates are approximately 4 to 37 percent $^{5}$. This high recurrence rate in palatal fistulas required a meticulous attention in management planning.

Due to complex nature of defect not a single technique addressed the problem Although small fistulae of the hard palate can often be repaired by local flaps, whereas large palatal fistulae require the transfer of non-palatal flaps e.g. regional intraoral, extra oral flaps and free flaps .and Prosthetic obturators .Use of tongue flap in palatal fistula management was first described by Guerrero-Santos and Altamirano ${ }^{9}$ in 
1966. subsequently Cadenat at al 11 in 1972 described the rich submucous vascular plexus in the tongue and demonstrated that tongue flaps could be raised safely in any direction. It has wide clinical applications in reconstruction of oral structures e.g. lips, floor of mouth, palatal and tonsillar defects. The tongue with its rich blood supply is a suitable and convenient source of such tissue ${ }^{12}$. Tongue flap closure for recurrent palatal fistula is associated with a relative lack of complications and a high success rate in children and adults ${ }^{13}$. In our Technique The flap is designed on the dorsal surface of the tongue in the midline. To close hard palate defects, an anteriorly based flap is created. The flap length and width kept a little more than the dimention of the fistulae. Result of this study have confirmed the reliability of tongue flap in recurrent palatal fistulas. The success rate in these case series i.e complete fistula closure was 36 of 40 (90 percent) this compares favorably with series reported by Guerrero-Santos and Altamirano in which success rate was 70 percent ${ }^{9}$, Pigott at al described success rate in fistula closure was 85 percent $^{14}$ and Enrina Diah with colleagues claimed the success rate in fistula closure was 90.5 percent ${ }^{15}$ when tongue flap was used in closure of the fistula. Leaking of fluid and food particles into the nose is troublesome and embarrassing for the patients. In our study all patients with palatal fistula are associated with nasal regurgitation. This social stigma was corrected in 95 percent of the patients while Pigott at al ${ }^{14}$ claimed that nasal regurgitation was corrected in all patients with the help of tongue flap.

Type and severity of cleft ${ }^{16}$ is directly associated to the recurrence of fistulation. In our study failure of fistula closure was more in larger defects(Fig 3). Four patients out of 40 ended in recurrence of fistulation and three belongs to patients group with larger size of fistula (more than $3 \mathrm{~cm}^{2}$ ). Two patients out of forty subjectively explained that they still had the problem of regurgitation of semi solid fluids and liguids into the nose. These two patients belonged to the palatal defect group more than $3 \mathrm{~cm}^{2}$. Some authors claimed that closure of nasal side of the fistula is an essential part of the repair ${ }^{3}$ other have negate this issue ${ }^{16}$ and observed that even when the nasal side of the repair is not sealed in a watertight fashion, healing of the fistula is still possible as tongue flap on the oral side encompasses the defect beyond the limits of the fistula. In our technique we close nasal layer by turning down oral layer in every case. This step facilitates nasal regurgitation correction. Among these patients fistula recurrence and regurgitation were more in larger defects. Wound dehiscence was noted in three cases and partial flap necrosis in one case. Previous literature described that extensive use of the diathermy ${ }^{15}$ can result thermal injury and may affect healing process. An extensive tongue movement is another contributory factor in wound dehiscence. Limitation of speech is encouraged to avoid undue tension on the pedicle ${ }^{13,17}$. Various authors described different methods of tongue fixation in order to avoid such mishaps. Guerrero-Santos and Femande $z^{18}$ used wire sutured to the tongue tip passed through and tied to the upper lip. Kruchinsky ${ }^{19}$ described fixation of side of the tongue to the premolars. Guerrero-Santos et al placed a kirschner wire placed through the angle of mandible, transfixing the body of the tongue. In our case series we used vicryl suture to tie the tongue flap in palatal defect. Some studies claimed to raise a large flap (5-6 cm long) to ensure its vascular viability and allow considerable tongue movement without undue tension on the pedicle ${ }^{13}$. This also eliminate the need of different tongue fixation procedures. In addition, aggressive palatal shelf exposure around the defect allows both a watertight oral-side closure and an increased surface area for in growth of new blood vessels before flap division..Single layer closure of fistula by anteriorly based pedicled tongue flap is therefore indicated in recurrent palatal fistula for correction of nasal regurgitation that cannot be successfully treated by other local or distant flaps because of the size and/or position of the defect ${ }^{20}$. 


\section{CONCLUSIONS}

Nasal regurgitation which is a social stigma can be effectively treated by anteriorly based tongue flap which is reliable as well as has higher success rate in the management of large, recurrent and recalcitrant palatal fistulas. Tongue remained mobile as it was and no articulation problems were noted. Repair of nasal layer by turnover palatal flap in not mandatory but has an added effect in correction of nasal regurgitation when used with tongue flap. By using tongue flap patients, having recurrent palatal fistula which remained untreated previously can be treated.

Copyright@ 02 Feb, 2013.

\section{REFERENCES}

1. Samanich J. Cleft palate. Pediatr Rev. Jun 2009; 30(6):230-2.

2. Sadhu P. Oronasal fistula in cleft palate surgery. Indian J Plast Surg. 2009; 42:123-8.

3. Ogle $\mathrm{OE}$, The management of oronasal fistulas in cleft palate patient. Oral Maxillofac Surg Clin North Am. 2002; 14(4): 553-62

4. Vlastos IM, Koudoumnakis E, Houlakis M, Nasika M, Griva M, Stylogianni E. Cleft lip and palate treatment of $\mathbf{5 3 0}$ children over a decade in a single centre. Int $\mathrm{J}$ Pediatr Otorhinolaryngol. 2009 Jul; 73(7):993-7.

5. Losken W, van Aalst J, Teotia S, Dean S, Hultman CS, Uhrich K. Achieving Low Cleft Palate Fistula Rates: Surgical Results and Techniques. Cleft Palate Craniofac J. 2010 Jul 1.

6. Phua YS, De Chlain T. Incidence of oronasal fistulae and velophrageal insuffiency after cleft palate repair, Cleft Palate Craniofacial Journal 2008; 45(1): 172-178.

7. Andersson E, Sandvik L, Semb G, Abyholm F. Palatal fistulas after repair of clefts of secondary palate. Scand J PlastRecons 2008; 42:296-9.

8. Murthy AS, Parikh PM, Cristion C, Thomassen M, Venturi M, Boyajian MJ. Fistula after 2-flap palatoplasty: a 20-year review. Ann Plast Surg. 2009 Dec; 63(6):632-5.
9. Guerrero-Santos, J., and Altamirano, J.T. The use of lingual flaps in repair of fistulas of the hard palate. Plast. Reconstr. Surg 1966; 38:123.

10. Abdollahi S, Jabbari BMY, Reza R, Ramin R. Results of difficult large palatal fistula repair by tongue flap. Rawal Med. J. 2008; 33:56-8.

11. Cadenat, H.,Combelle,R.,and Fabie,M. Lambeaux de langue, vascularisation, morphologie et utilization. Ann. Chir Plast 1973; 18:223.

12. Bracka, E.: The blood supply of the dorsal tongue flaps. Br. J. Plastic Surg. 1980; 34:379.

13. Posnick JC, Getz SB Jr. Surgical closure of end stage palatal fistulas using anteriorly based dorsal tongue flaps. J Oral Maxillofac Surg 1987; 45(11): 907-912.

14. Pigott RW, Rieger FW, Moodie AF. Tongue flap repair of cleft palate Fistulae. $\mathrm{Br}$ J Plast Surg 1984; $37: 285-293$

15. Diah E, Lo LJ, Yun C, Wang R, Wahyuni LK, Chen YR. Cleft oronasal fistula: A review of treatment results and a surgical management algorithm proposal. Chung Gang Med J 2007; 30:529-37.

16. Losee JE, Smith DM, Afifi AM, Jiang S, Ford M, Vecchione $L$, et al. A successful algorithm for limiting postoperative fistulae following palatal procedures in the patient with orofacial clefting. Plast Reconstr Surg 2008;122:544-54.

17. Randall, $P$. Management and timing of cleft palate fistula repair (Discussion). Plast. Reconstr. Surg. 1986; $78: 746$.

18. Guerrero-Santos J, Femandez JM. Further experience with tongue flaps in cleft palate repair. Cleft palate $\mathrm{J}$ 1973; 10:192-202.

19. Kruchinsky GV, A new method of palat defect repair. Acta chir plast 1971; 14:23-29.

20. Babu C, Rai B, Nair A M, Meenakshi. Single layer closure of palatal fistula using anteriorly based dorsal tongue flap. J Maxillofac Oral Surg 2009; 8(2):199-200. 
AUTHOR(S):

1. DR. IRFAN ISHAQ

Registrar

Department of Plastic Surgery

Services Institute of Medical Sciences, Lahore.

2. PROF. GHULAM QADIR FAYYAZ

MBBS, M.S, D.S.S.

Head Department of Plastic Surgery

Services Institute of Medical Sciences, Lahore
Correspondence Address:

Dr. Irfan Ishaq

Registrar

Department of Plastic Surgery

Services Institute of Medical Sciences, Lahore.

drirfan146@yahoo.com

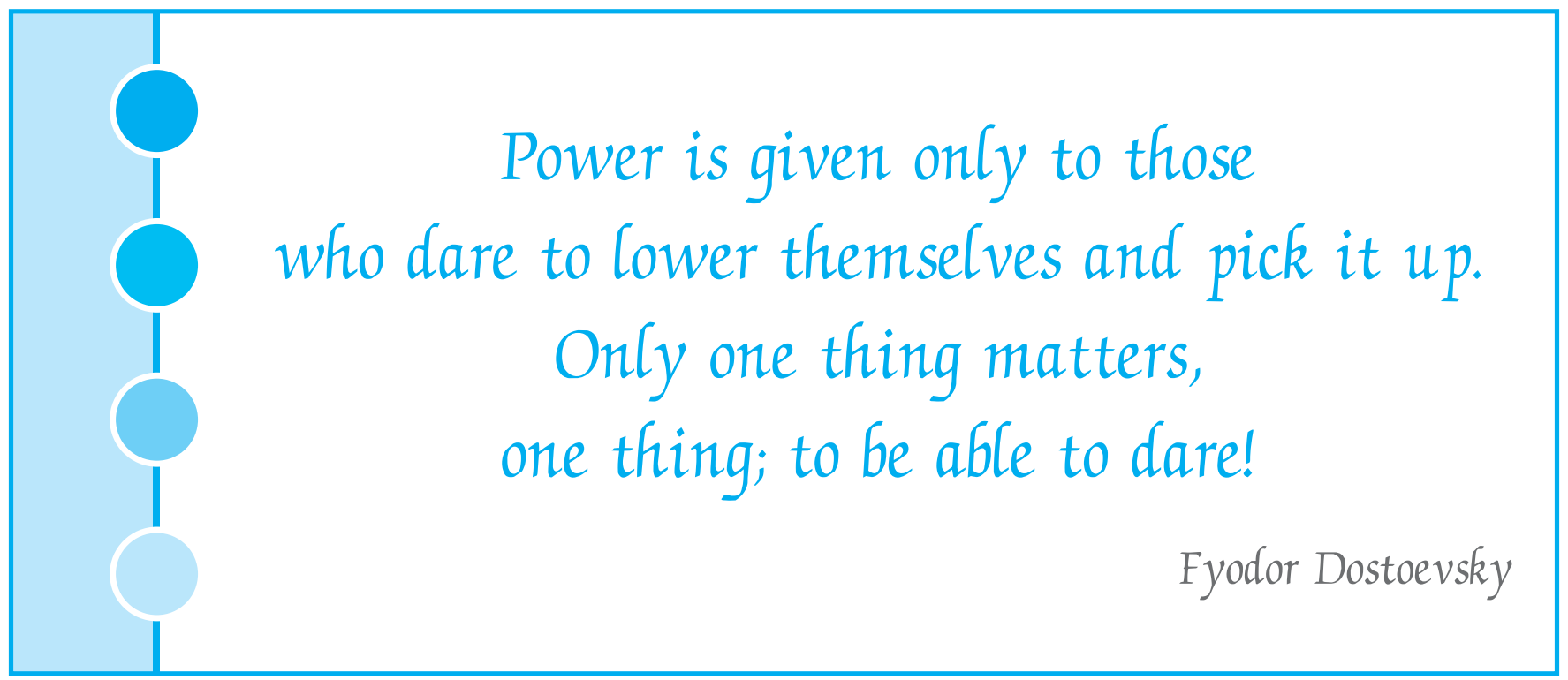

